\title{
Gender Gap in STEM: A Cross-Sectional Study of Primary School Students' Self-Perception and Test Anxiety in Mathematics
}

\author{
Natalia Ayuso $^{\circledR}$, Member, IEEE, Elena Fillola, Belén Masiá, Member, IEEE, \\ Ana C. Murillo $^{\circledR}$, Member, IEEE, Raquel Trillo-Lado, Sandra Baldassarri, Senior Member, IEEE, \\ Eva Cerezo $\left.{ }^{(}\right)$Member, IEEE, Laura Ruberte, M. Dolores Mariscal, and María Villarroya-Gaudó
}

\begin{abstract}
Contribution: Significant gender differences are 2 observed on primary school students' perception of self-efficacy 3 and test anxiety in mathematics. Girls perceive themselves to be 4 significantly worse than boys in mathematics and report higher 5 test anxiety toward mathematics exams. Gender differences in 6 self-efficacy become more pronounced as students grow up, and 7 test anxiety increases for all students. However, the present study 8 shows that teachers' do not perceive differences in self-efficacy 9 in mathematics between boys and girls.

Background: The low presence of women in science, technol1 ogy, engineering, and mathematics (STEM) might be explained 12 by the attitude of young students toward mathematics. Different 3 studies show that girls are less interested in STEM areas than 4 boys during secondary school. A study on the reasons for this 15 fact pointed out that the early years of education can provide 16 a relevant insight to reverse the situation.

Research Questions: Is there any age-dependent gender differ8 ence in primary school students in aspects related to mathemat19 ics? Are teachers aware of students' perceptions?

Methodology: This work presents a study of over 2000 pri1 mary school students (6-12 years old) and 200 teachers in 22 Aragón (Spain). The study consists of a survey on aspects that 23 influence the experience of female and male students with math24 ematics and Spanish language for comparison purposes and 25 teacher's awareness of students' perception.

Findings: The present study shows that during primary school, 27 girls are more likely to experiment a negative attitude toward 28 mathematics than boys as they grow up, and teachers may not 29 perceive girls' situation.
\end{abstract}

Manuscript received October 10, 2019; revised April 24, 2020; accepted June 13, 2020. This work was supported in part by the Spanish Woman's and Equal Opportunities Institute (10/2ACT); in part by the Gender and Equality Chair from the University of Zaragoza and the Aragón Woman's Institute from the Aragón Government; in part by the Spanish Foundation for Science and Technology, FECyT, of the Spanish Ministry of Science and Innovation under Grant FCT-18-13481; in part by the European Union through DyViTo under Grant 765121; in part by the TRAFAIR Project under Grant 2017-EU-IA-0167; in part by MINECO/AEI/ERDF under Grant TIN201676635-C2-1-R, Grant PID2019-105660RB-C21, Grant RTI2018-096986-BC31, and Grant DPI2016-76676-R; in part by the Aragón Government (research groups: T58_20R, T45-17R, T60-20R); and in part by ERDF 2014-2020. (Corresponding author: Natalia Ayuso.)

Natalia Ayuso, Belen Masiá, Ana C. Murillo, Raquel Trillo-Lado, Sandra Baldassarri, Eva Cerezo, Laura Ruberte, M. Dolores Mariscal, and María Villarroya-Gaudó are with the School of Engineering and Architecture, University of Zaragoza, 50018 Zaragoza, Spain (e-mail: nayuso@unizar.es).

Elena Fillola is with the Department of Mathematics, University of Bristol, Bristol BS8 1TH, U.K.

Digital Object Identifier 10.1109/TE.2020.3004075
Index Terms-Mathematics, primary school, science, technol- 30 ogy, engineering, and mathematics (STEM) studies, women in engineering.

\section{INTRODUCTION}

$\mathbf{T}$ HE SCIENCE, technology, engineering, and mathematics (STEM) study areas are key to economic growth and innovation and have acquired special relevance in the ecosystem of the digital economy [1]. In this context, the scarce presence of women in these areas is especially visible and worrisome worldwide, especially in math-intensive fields, such as engineering and even more in computer engineering as different recent studies have shown [2]-[4].

Furthermore, even when girls do graduate from scien- 42 tific fields, they are much less likely than boys to work ${ }_{43}$ as professionals in those fields. In the European Union, ${ }_{44}$ women were just $16.7 \%$ of those employed in the high and med-technological sector in 2016 [5]. In the United States, they accounted for one-fifth or less of those employed in some of these jobs, including $20.0 \%$ of software developers, $9.7 \%$ of computer network architects, and $7.8 \%$ of aerospace engineers [6].

According to the Organization for Economic Co-operation 51 and Development (OECD), workers who have completed 52 higher education in STEM areas are more successful in the ${ }_{53}$ labor market than other workers, even over those workers who ${ }_{54}^{54}$ have completed other university degrees: the employment rate ${ }_{55}$ for those with STEM higher education is $83.0 \%$ over the aver- 56 age $66.6 \%$, and presents a lower unemployment rate of $9.4 \%$ over the average $17.9 \%$, in 2016 . Therefore, the lack of women accessing STEM studies reduces the number of females in professions with prestige and greater purchasing power and therefore deprives them of greater independence. Moreover, the fact that there are few women working in STEM disciplines is detrimental to society as a whole because the community 63 lacks the views, ideas, creativity, work, and knowledge of half ${ }_{64}$ of the population. The seriousness of this situation has led 65 institutions, such as the EU or the OECD to encourage the 66 recruitment of women in these fields, and in 2016, the United 67 
${ }_{68}$ Nations established February 11th to be the International Day 69 of Women and Girls in Science.

70 Almost $60 \%$ of female students at high school have no 71 interest in studying engineering, while for male students 72 this percentage is down to $35 \%$ [7]. A variety of reasons 73 have been suggested for girls' lack of interest in STEM 74 areas [3], [8], [9]. Both boys and girls report that little is 75 known about the engineering profession [7], but girls hold 76 fewer positive views than boys about the areas of computer sci77 ence or information and technology [10]. Some causes have 78 a clear social component, such as the stereotypes installed 79 since childhood [11], the lack of family support, and the so absence of references [7]. Stereotypes lead people to believe 81 that the innate intelligence or brilliance required for mathe82 matics or engineering fields are male attributes [12]. Teachers 83 present implicit stereotypes toward gender differences in math84 ematical ability that are not present in other subjects or toward 85 other factors such as race [13]. These stereotypes in a stu86 dent's close environment may have an immediate effect on 87 their interests at early ages [14], leading girls and women to 88 avoid mathematics or engineering, and also causing people to ${ }_{89}$ subconsciously believe that women cannot be good in these 90 fields.

91 Regarding reasons grounded in cognitive aspects, recent 92 research is converging toward the notion that gender differ${ }_{93}$ ences in STEM are not due to differences in absolute cognitive 94 ability but rather to differences in the breadth of cognitive 95 ability [15], [16]. A study compared gifted individuals and 96 showed that those with higher mathematical skills relative to 97 verbal skills are more likely to pursue STEM careers, while 98 individuals with comparatively high mathematical and ver99 bal abilities are more likely to purse a non-STEM career [9]. 100 Therefore, as math-talented women tend to also have good 101 verbal abilities, they are more likely to choose challeng102 ing non-STEM fields that are more practical or applied, as 103 opposed to math-intensive fields that are more theoretical or 104 mechanical [3]. Different works also confirm the importance 105 of mathematics when choosing engineering as a career [17].

106 Herbert and Stipek [10] conducted a longitudinal study over 107300 children from 5 to 10 years old in the United States 108 to observe gender differences concerning math and literacy, 109 including teachers' and parents' ratings. All participant chil110 dren came from low-income families. The results show that 111 starting at 7-8 years of age, girls rated themselves lower than 112 boys at math, despite math achievements and teachers' rat113 ings not showing gender differences. However, parents' ratings 114 of children's competence strongly influenced children's self115 perceived efficacy in math. According to research carried out 116 in Spain following 1500 students for six years, from age 14 to 11719 [18], girls tend to underestimate their competence in tech118 nology and mathematics even though they have better grades 119 than boys. In contrast, boys tend to overestimate their skills 120 in these same subjects. The research concludes that there is 121 a clear gender gap in the perception of competences in subjects 122 related to science, technology, and mathematics.

123 Besides perceived competence, Ramirez et al. [19] high124 lighted that anxiety negatively affects children's achievements 125 in mathematics as early as the first and second grades
(6-8 years old). The stress caused by math exams can nega- 126 tively affect both results and interest in this subject. In this ${ }^{127}$ sense, emotions have been recognized as critically impor- ${ }_{128}$ tant to students' learning, motivation, academic achievement, ${ }_{129}$ and health [23], [24]. Positive activating emotions, as stu- ${ }_{130}$ dents' interest in a subject, are also related to academic ${ }_{131}$ achievements [19], [25], [26].

For primary- and elder-school students, the findings in ${ }_{133}$ PISA [21] 2012 and, for instance, of O'Keeffe et al. [22] ${ }_{134}$ showed that girls report higher levels of math anxiety than 135 boys. Young et al. [20] showed that math anxiety disrupts 136 and divides working memory resources and that individuals ${ }_{137}$ with higher levels of math anxiety have less working memory ${ }_{138}$ to focus on mathematical activities and several authors argue ${ }_{139}$ that students who experience mathematics anxiety generally 140 avoid mathematics, mathematics courses, and career paths that ${ }_{141}$ require the mastery of some mathematical skills [27]-[30]. ${ }_{142}$

In addition, it was proven that teachers have a strong ${ }_{143}$ influence on the students' life, from academic achievements 144 to emotions experimented in the classroom [31]-[33], with 145 stronger influences exerted in younger students [34]. The ${ }_{146}$ teachers' attitude and interpersonal relations with students 147 drive students' emotional experiences. Many works have ana- 148 lyzed the relationship between achievements in mathematics 149 and teachers' emotions and attitudes [19], [35], as well as 150 between teachers' attitude toward science and their pupils' ${ }_{151}$ attitude [36]. The gender of the teacher is also relevant in ${ }_{152}$ this relationship: female teachers with high levels of anxi- ${ }_{153}$ ety toward mathematics or negative attitudes toward science, 154 lead female pupils to perform worse and have a worse ${ }_{155}$ opinion of science than male students or pupils with male 156 teachers [34]-[36].

In light of the foregoing considerations, the present work ${ }_{158}$ intends to cover the gap found in previous studies, focus- 159 ing on the evolution during primary school (6-12 years old) 160 of aspects that influence the experience with mathematics 161 of female and male students from any socioeconomic sta- 162 tus. The work also considers teachers' awareness of children's 163 autoperceptions because the regional evaluations show no rel- ${ }_{164}$ evant differences in mathematical competence by sex at the 165 completion of primary education [37].

The remainder of this article is organized as follows. 167 Section II presents methodology and sample. Section III 168 investigates gender differences along with primary school 169 regarding students' perceptions toward mathematics and teach- 170 ers' awareness toward classroom climate. The results obtained 171 are discussed in Section IV. Conclusions and future actions 172 devised from present outcomes are given in Section V.

\section{Methodology and Sample}

\section{A. Background}

175

The present study analyzes 2137 questionnaires answered 176 by primary-school students (48.7\% female and 51.3\% male) 177 and 212 questionnaires filled in by their teachers $(75.5 \% \quad 178$ female and $24.5 \%$ male). The surveys were completed at 179 schools that had carried out the outreach activity titled 180 "Una Ingeniera en Cada Cole" ("A Female Engineer in Every ${ }_{181}$ 


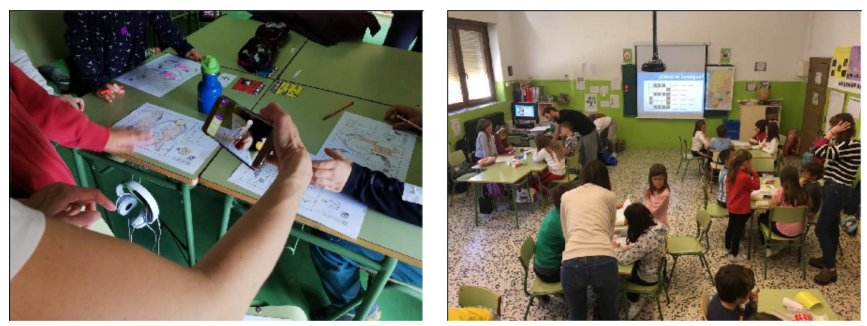

Fig. 1. Photographs taken during "A Female Engineer in Every School 2019" workshops. Left: "Augmented Reality" workshop participants coloring a human body page featured for an augmented reality app. Right: "How are images stored in computers?" workshop participants encoding/decoding simple images with pixel values.

182 School") from March to May 2018 [38]. This activity was 183 founded after a group of female faculty members from the ${ }_{184}$ University of Zaragoza realized that activities to encourage 185 high-school students to pursue engineering degrees were often 186 ineffective, as the students had already chosen a study path187 way. The need to direct activities to younger pupils was 188 identified, and "A Female Engineer in Every School" started 189 in 2016.

190 In these series of events, female engineers, both from aca191 demic and industry backgrounds, visit primary schools, when 192 possible with some kind of personal link, so that children 193 can see her as a close example. The engineers show their 194 work to children through open and interactive workshops 195 where students in groups are asked to build or design some 196 technology-related project (see Fig. 1). The workshops are cre197 ative, collaborative, and open so that each group creates their 198 own designs or suggests their solutions, encouraging students' 199 effectiveness and self-perception. The workshops were shaped 200 after research showing that girls tend to prefer working in 201 small groups and learning through practical activities, and also 202 that they feel more confident and obtain better results when 203 teamworking and working in open problems [39]-[41].

204 The activity's focus depends on the area of expertise of 205 the visiting engineer and the children's age group. Examples 206 include "resistant structures with beautiful and tasty materi207 als" [42], "a polyethylene thermocutter" [43], "how do we 208 clean water?" [44], "augmented reality" [45], or "how are 209 images stored in computers?" [46].

210 Before the activity with children, teachers were also 211 involved through discussions about their opinions on STEM 212 subjects, the education of their students, and the activity 213 developed.

${ }_{214}$ After 2016 and 2017 editions, the engineers realized that 215 many primary school teachers were not aware of the lack 216 of women in engineering studies. In addition, some teach217 ers reported that many girls from the age of 9 started to 218 show less interest in mathematics and technology than boys. ${ }_{219}$ Consequently, a new feature was added to the activity: a sur220 vey investigating the students' approach to mathematics, as 221 it is often directly linked to STEM career choices. In addi222 tion, teachers' perceptions are also gathered and compared 223 to students' ones, as teachers' beliefs can influence social 224 interactions in the classroom life.

\section{B. Questionnaires}

225

Students were asked to fill in a questionnaire about cogni- 226 tive test anxiety and self-perception, although the wording was 227 simplified in an attempt to match the developmental level of ${ }_{228}$ the students participating (e.g., S6-I worry whenever I have 229 a mathematics test. Instead of a more formal wording such as I 230 have high anxiety levels when I have a cognitive evaluation on 231 math-related topics). Teachers received a wider range of ques- 232 tion topics, mostly to gather their preferences and strategies 233 to teach different subjects and their thoughts about students' ${ }^{234}$ understanding of mathematics. The results of these question- ${ }^{235}$ naires are the subject of this report. The questionnaires for ${ }_{236}$ both teachers and students had two parts as follows. 237

1) The first part gathered profiling information, such as 238 gender, age, and previous studies in the case of the teach- 239 ers. A survey was considered valid only if the first part 240 was completed correctly.

241

2) The second part involved statements related to subjects, 242 perceived ability of the students, and anxiety toward ${ }_{243}$ exams. Responses were given in the form of Likert-scale 244 ratings.

The questionnaire for students comprised eight 1-item mea- 246 sures, questions $S 1-S 8$. Despite the questionnaire not being 247 designed as a single scale, in questions $S 6-S 8$ (S6-I worry ${ }^{248}$ whenever I have a mathematics test; $S 7$-I worry whenever 249 I have a Spanish language test; and S8-I worry whenever 250 I have a test, no matter the subject), where students' con- 251 cern with exams can be the underlying factor, Cronbach's 252 alpha yields a value of 0.8770 , suggesting a good internal con- 253 sistency. The teachers' questionnaire comprised seven 1-item ${ }_{254}$ measures, $T 1-T 7$.

For convenience and to maximize the number of partici- 256 pants, schools were given the choice to complete the surveys 257 before or right after the activity or on a follow-up session. As 258 the survey was focused on students' and teachers' perceptions, 259 not on the activity, the moment the survey was completed did 260 not affect the answers.

\section{Sample Characterization}

262

The survey was completed in 39 educational centers, 30 in 263 cities, and nine in rural areas, both in public and private 264 schools.

Teachers: Out of 156 teacher surveys received, 143 were 266 considered valid for data analysis and $58.7 \%$ were from 267 public schools. The respondents included $75.5 \%$ of women 268 and $42.7 \%$ of the respondents took science-based studies 269 before going to college (as opposed to a humanities-based or 270 arts-based studies).

Students: 2148 student surveys were gathered, out of which 272 2137 were valid for the data analysis. Students were divided 273 into stages according to their academic school years: the 274 first stage for children in first and second years of primary 275 school (ages 6-8), second stage for children in the third and 276 fourth years of primary school (ages 8-10), and third stage 277 for children in the last two years of primary school, fifth and 278 sixth (ages 10-12). Table I comprises the student count and 279 percentage for each stage, segregated by sex. 
TABLE I

Students' Count By STAGe AND Gender

\begin{tabular}{lllllll}
\hline \hline Stage & $\begin{array}{l}\text { Girls } \\
\text { (count) }\end{array}$ & $\begin{array}{l}\text { Boys } \\
(\text { count) }\end{array}$ & $\begin{array}{l}\text { Total } \\
(\text { count) }\end{array}$ & $\begin{array}{l}\text { Girls } \\
(\%)\end{array}$ & $\begin{array}{l}\text { Boys } \\
(\%)\end{array}$ & $\begin{array}{l}\text { Total } \\
(\%)\end{array}$ \\
\hline $1^{\text {st }}$ & 152 & 175 & 327 & 7.1 & 8.2 & 15.3 \\
$2^{\text {nd }}$ & 381 & 360 & 741 & 17.8 & 16.8 & 34.7 \\
$3^{\text {rd }}$ & 509 & 560 & 1069 & 23.8 & 26.2 & 50 \\
\hline $\begin{array}{l}\text { Total } \\
\text { (count) }\end{array}$ & 1042 & 1095 & 2137 & 48.7 & 51.2 & 100 \\
\hline \hline
\end{tabular}

281 Out of all students, $48.8 \%$ were girls and $64.4 \%$ attended 282 a public school. Note that these percentages are within less 283 than $5 \%$ of the official statistics provided by the Regional ${ }_{284}$ Government [47] about primary-school students in the region, 285 which confirms that the sample is an accurate representation of 286 the relevant population for this study. The present results can ${ }_{287}$ also be generalized to the rest of Spain, due to the uniformity 288 in student distribution around the country [48].

\section{RESULTS}

290 For every question, ratings in a five-point Likert scale 291 with scores 1-never, 2-rarely, 3-sometimes, 4-very often, 292 and 5-always, are collected. Questions are analyzed and 293 discussed independently, using a two-way analysis of vari294 ance (ANOVA) to test whether our two factors (gender and 295 stage) have an influence on the observed data. Significant 296 effects are further analyzed by using a Tukey-Kramer post 297 hoc analysis, which allows us to test pairwise comparisons. 298 In all tests, a $p$-value below 0.05 is considered to indicate 299 significance.

\section{A. Students' Preferences and Perceptions Along Primary ${ }_{301}$ School}

${ }_{302}$ This section presents students' beliefs concerning math and 30з Spanish language to highlight gender differences along the 304 primary school years that can explain the scarce presence of 305 women pursuing STEM studies: preferences, self-efficacy, and 306 test-anxiety of math and language. In addition, the perceived 307 usefulness of mathematics has been also considered as a factor 308 that influences the students' experience of positive activating 309 emotions [49].

$310 \quad$ 1) Preference of Math Versus Spanish Language: Students' 311 preference for math versus Spanish language was tested 312 through question $S 1$ (I prefer Spanish language to math). Both 313 gender and stage had a significant effect on the answers while 314 the interaction of both did not (see Table II). When looking 315 into the post hoc tests, it shows that gender drives the main 316 differences: from the second stage on, girls show a stronger 317 agreement with the statement than boys. Looking at the 95\% 318 confidence interval for the mean rating of girls and boys in the 319 second and third stages, those of the girls are above the neutral 320 answer (3-sometimes), and those of the boys are below the 321 neutral answer (see Table III), separated by gender and stage, 322 suggesting that boys prefer math to Spanish language, whereas 323 girls prefer the Spanish language to math, with a significant 324 difference between genders.
TABLE II

ANOVA Results For Preference Among SubJects For the Students' Answers to $S 1$ (I Prefer Spanish Language to Math) and $S 2$ (I Like Natural Science Better Than Social Science)

\begin{tabular}{c||c|c|c||c|c|c}
\hline \multicolumn{1}{c||}{} & \multicolumn{3}{c||}{$\mathrm{S} 1$} & \multicolumn{3}{c}{$\mathrm{S} 2$} \\
& $\mathrm{~F}$ & $\left(d f_{1}, d f_{2}\right)$ & $\mathrm{p}$ & $\mathrm{F}$ & $\left(d f_{1}, d f_{2}\right)$ & $\mathrm{p}$ \\
\hline Gender & 37.88 & $(1,2111)$ & $0.0000^{*}$ & 2.40 & $(1,2112)$ & 0.1216 \\
Stage & 4.84 & $(2,2111)$ & $0.0008^{*}$ & 1.12 & $(2,2112)$ & 0.3251 \\
Gender $\times$ Stage & 0.24 & $(2,2111)$ & 0.7905 & 1.39 & $(2,2112)$ & 0.2505 \\
\hline
\end{tabular}

$\mathrm{F}$ is the F-statistic, a measure of the ratio of the variance accounted for and the unexplained variance; $d f_{1}$ and $d f_{2}$ are the degrees of freedom for the effect of the factor (Gender, Stage, or the interaction) and the residuals, respectively; $p$ is the associated p-value given the F-statistic and the degrees of freedom.

TABLE III

95\% CONFIDENCE INTERVALS FOR THE STUDENTS' ANSWERS TO $S 1$ (I Prefer SPANish Language to Math)

\begin{tabular}{c|c||c|c||c|c}
\hline \multicolumn{2}{c}{$1^{\text {st }}$ stage } & \multicolumn{2}{c}{$2^{\text {nd }}$ stage } & \multicolumn{2}{c}{$3^{\text {rd }}$ stage } \\
Boys & Girls & Boys & Girls & Boys & Girls \\
\hline$(2.91,3.31)$ & $(3.23,3.66)$ & $(2.66,2.94)$ & $(3.12,3.39)$ & $(2.70,2.92)$ & $(3.12,3.35)$ \\
\hline
\end{tabular}
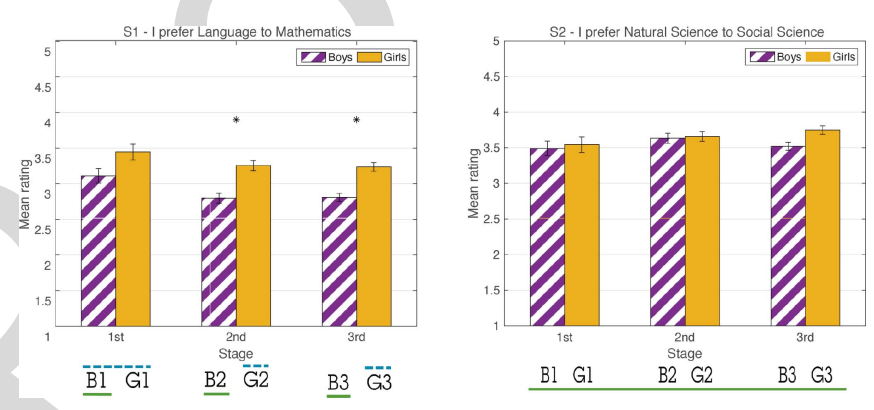

Fig. 2. Preference among subjects. Left: mean ratings for $S 1$ (I prefer Spanish language to math). Right: mean ratings for $S 2$ (I prefer natural sciences to social sciences). Error bars show standard error of the mean. Significant differences between both genders are marked with an asterisk. Girls' preference for Spanish language versus math is stronger than boys' preference from the second stage on, whereas no significant difference between genders is observed for natural versus social sciences. Below each graph, the results of the pairwise comparisons are shown for the corresponding question: items in the same group (i.e., marked by the same type of horizontal line) have no statistically significant differences between them. For each item, the letter refers to the gender ( $B$ : boys and $G$ : girls), and the number to the stage. On the left, $B 1, B 2$, and $B 3$ form one group (continuous line), while $B 1, G 1, G 2$, and $G 3$ form another group (dotted line). On the right, there is one single group comprising all six items (continuous line).

As an additional comparison to better put in context the 325 findings from $S 1$, the responses to $S 2$ (I like natural sciences 326 better than social sciences) were analyzed. $S 2$ asks about the ${ }_{327}$ preference of natural versus social sciences, two distinct sub- 328 jects in the Spanish primary school curriculum so students ${ }_{329}$ can differentiate them easily. There were no significant effects $3 з 0$ of gender or stage in the students' answers in this case (see ${ }_{331}$ Table II and Fig. 2).

The findings are summarized as follows.

1) From the second stage on, on an average, boys prefer 334 math to Spanish language, whereas girls prefer Spanish 335 language to math, with a significant difference between 336 genders.

2) No difference between genders nor stage is observed, in 338 contrast, for natural sciences versus social sciences. 


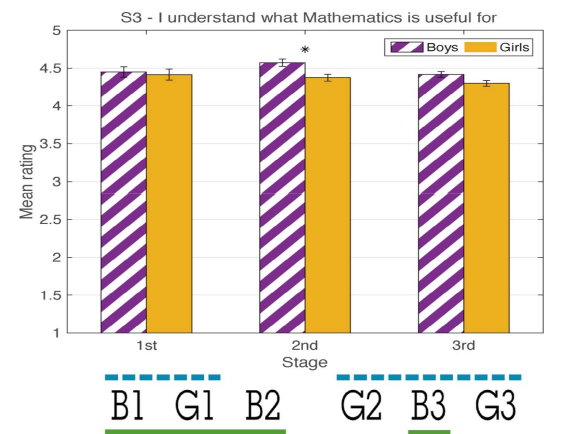

Fig. 3. Perceived usefulness of math, in the form of mean ratings for $S 3$ (I understand what mathematics is useful for). Error bars show the standard error of the mean. Significant differences between both genders are marked with an asterisk. Only in the second stage, there is a significant difference between boys' and girls' answers. Below the graph, results for the pairwise comparisons are shown for the corresponding question (refer to the caption in Fig. 2).

TABLE IV

ANOVA Results for PERCEIVEd Usefulness of MATHEMATICS FOR THE STUDENTS' ANSWERS TO $S 3$ (I UNDERSTAND WHAT MATHEMATICS ARE USEFUl FOR)

\begin{tabular}{c||c|c|c}
\hline \multicolumn{1}{c||}{} & \multicolumn{3}{c}{$\mathrm{S} 3$} \\
& $\mathrm{~F}$ & $\left(d f_{1}, d f_{2}\right)$ & $\mathrm{p}$ \\
\hline Gender & 7.13 & $(1,2116)$ & $0.0077^{*}$ \\
Stage & 3.76 & $(2,2116)$ & $0.0235^{*}$ \\
Gender $\times$ Stage & 0.97 & $(2,2116)$ & 0.3800 \\
\hline
\end{tabular}

$340 \quad 2$ ) Usefulness of Mathematics: Question S3 (I understand 341 what mathematics is useful for) covers the understanding of 342 math usefulness. It is assumed here that understanding its use343 fulness correlates with considering them useful. Since the first 344 stage of education, mathematics is clearly perceived as being 345 very useful (see Fig. 3). While both gender and stage have 346 a significant effect on the answers (see Table IV), a look at 347 the post hoc tests reveals that the only significant difference 348 between boys and girls is found in the second stage, in which 349 boys rate the usefulness of mathematics higher than girls. The 350 interaction effect between gender and stage is nonsignificant 351 (Table IV), indicating that there is no sign that boys' and girls' 352 responses are influenced differently by the stage.

$\left.{ }_{353} 3\right)$ Self-Perceived Efficacy in Math Versus Spanish 354 Language: Self-perceived efficacy in both math and Spanish 355 language has been explored through questions S4 (I am good 356 at math) and S5 (I am good at Spanish language).

357 Both for $S 4$ and $S 5$, a significant effect was found for gender 358 (see Table V). The post hoc analysis reveals that in the first 359 stage there is no significant difference between genders for 360 any of the two questions, with differences between genders 361 arising in the second and third stages. In the second stage, 362 boys rate themselves significantly better at math than girls do ${ }_{363}(p<0.0001)$; estimated means are $\mu_{B 2}=4.24$ versus $\mu_{G 2}=$ 364 3.81. This trend continues in the third stage, in which boys also 365 rate themselves significantly better at math $(p<0.0001)$, with 366 estimated means $\mu_{B 3}=3.96$ versus $\mu_{G 3}=3.60$. In Spanish 367 language, the result is the opposite. Girls rated themselves 368 significantly better than boys did in the second and third stages
TABLE V

ANOVA RESUlts FOR SElF-PERCEIVEd EFFicACy FOR THE STUdENTS' ANSWERS TO $S 4$ (I AM GOOD AT MATH) AND $S 5$ (I AM GOOD AT SPANISH LANGUAGE)

\begin{tabular}{c||c|c|c||c|c|c}
\hline \multicolumn{1}{c||}{} & \multicolumn{3}{c||}{$\mathrm{S} 4$} & \multicolumn{3}{c}{$\mathrm{S} 5$} \\
& $\mathrm{~F}$ & $\left(d f_{1}, d f_{2}\right)$ & $\mathrm{p}$ & $\mathrm{F}$ & $\left(d f_{1}, d f_{2}\right)$ & $\mathrm{p}$ \\
\hline Gender & 41.24 & $(1,2101)$ & $0.0000^{*}$ & 13.60 & $(1,2089)$ & $0.0002^{*}$ \\
Stage & 19.86 & $(2,2101)$ & $0.0000^{*}$ & 28.87 & $(2,2089)$ & $0.0000^{*}$ \\
Gender $\times$ Stage & 1.84 & $(2,2101)$ & 0.1594 & 0.71 & $(2,2089)$ & 0.4927 \\
\hline
\end{tabular}

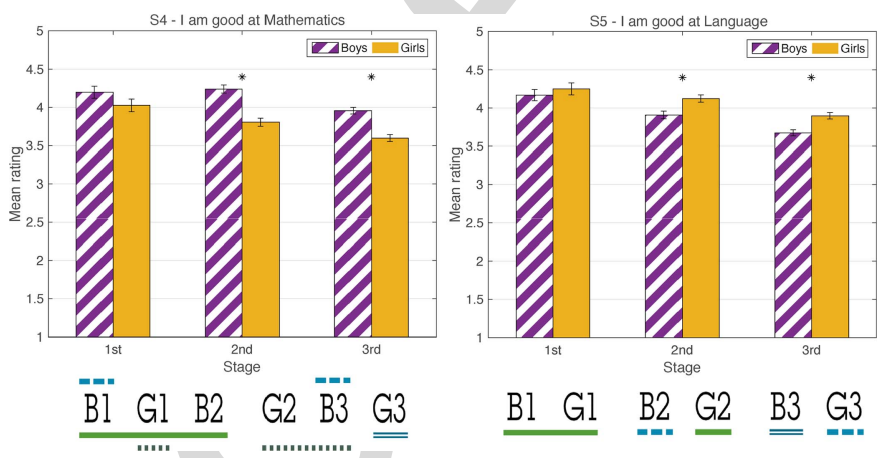

Fig. 4. Self-perceived efficacy. Left: mean ratings for $S 4$ (I am good at math). Right: mean ratings for S5 (I am good at Spanish language). Error bars show the standard error of the mean. Significant differences between both genders are marked with an asterisk. From the second stage on, boys provide significantly higher ratings than girls in math, while the opposite happens for Spanish language. Below each graph, results for the pairwise comparisons are shown for the corresponding question (refer to the caption in Fig. 2).

( $p=0.0249$ for the second stage and $p=0.0018$ for the third ${ }_{369}$ one); estimated means are $\mu_{B 2}=3.91$ versus $\mu_{G 2}=4.12$ and 370 $\mu_{B 3}=3.67$ versus $\mu_{G 3}=3.90$. Fig. 4 shows estimated means ${ }_{371}$ for both questions, separated by gender and stage; significant 372 differences are marked on the graphs.

373

A significant influence of the stage is found, as well for both 374 questions (see Table V). The interaction effect between gender 375 and stage is nonsignificant in both questions, indicating that 376 there is no sign that boys' and girls' responses are influenced 377 differently by the stage.

Additionally, there is a certain correlation between the self- 379 perceived efficacy of children in a specific subject (e.g., math 380 or Spanish language) and the preference of children for that 381 subject. Specifically, the correlation between answers to $S 1$ and ${ }_{382}$ $S 4$ and answers to $S 1$ and $S 5$ has been tested for each gender ${ }_{383}$ group in the second and third stages. A weak correlation was 384 found between the answers in all cases, with $p$-values allowing ${ }_{385}$ to assert that there is indeed a correlation (see Table VI). The ${ }_{386}$ sign of the correlation (negative for $S 1-S 4$ and positive for $S 1-{ }_{387}$ $S 5$ ) is indicative of this relationship between preference and ${ }_{388}$ self-perceived efficacy since $S 1$ asks about the preference of 389 language over math, $S 4$ about self-perceived efficacy in math, 390 and $S 5$ about self-perceived efficacy in language. 391

4) Test Anxiety: Regarding students' concern about math 392 and Spanish language tests, the answers to statements $S 6$ ( $I{ }_{393}$ worry whenever I have a mathematics test), S7 (I worry 394 whenever I have a Spanish language test), and S8 (I worry 395 
TABLE VI

SPEARMAN CoRrelation COEFFicient $(\rho)$ AND Associated P-VAlue BETWEeN ANSWERS TO $S 1$ AND $S 4$, AND BETWEEN $S 1$ AND $S 5$, Segregated by Gender Group and Stage, for Stages With A SIGNIFICANT DifFERENCE IN GENDER

\begin{tabular}{c|c||c|c||c|c}
\hline & \multicolumn{2}{c}{} & \multicolumn{2}{c}{$2^{\text {nd }}$ stage } & \multicolumn{2}{c}{$3^{\text {rd }}$ stage } \\
& & Boys & Girls & Boys & Girls \\
\hline \multirow{2}{*}{ S1-S4 } & $\rho$ & -0.2848 & -0.3033 & -0.3750 & -0.3446 \\
& p-val & $<0.0001^{*}$ & $<0.0001^{*}$ & $<0.0001^{*}$ & $<0.0001^{*}$ \\
\hline \multirow{2}{*}{ S1-S5 } & $\rho$ & 0.2465 & 0.3533 & 0.3074 & 0.2680 \\
& p-val & $<0.0001^{*}$ & $<0.0001^{*}$ & $<0.0001^{*}$ & $<0.0001^{*}$ \\
\hline
\end{tabular}

TABLE VII

ANOVA RESUlTS FOR TEST ANXIETY FOR THE STUDENTS' ANSWERS TO $S 6$ (I WORRY WHENEVER I HAVE A MATHEMATICS TEST), $S 7$ (I WORRY WHENEVER I HAVE A SPANISH LANGUAGE TEST), AND $S 8$ (I WORRY WHENEVER I HAVE A TEST)

\begin{tabular}{c||c|c|c||c|c|c||c|c|c}
\hline \multicolumn{1}{l|}{} & \multicolumn{3}{c||}{$\mathrm{S} 6$} & \multicolumn{3}{c||}{$\mathrm{S} 7$} & \multicolumn{3}{c}{$\mathrm{S} 8$} \\
& $\mathrm{~F}$ & $\left(d f_{1}, d f_{2}\right)$ & $\mathrm{p}$ & $\mathrm{F}$ & $\left(d f_{1}, d f_{2}\right)$ & $\mathrm{p}$ & $\mathrm{F}$ & $\left(d f_{1}, d f_{2}\right)$ & $\mathrm{p}$ \\
\hline Gender & 53.40 & $(1,2057)$ & $0.0000^{*}$ & 3.87 & $(1,2052)$ & 0.0493 & 27.50 & $(1,2064)$ & $0.0000^{*}$ \\
Stage & 27.19 & $(2,2057)$ & $0.0000^{*}$ & 58.05 & $(2,2052)$ & $0.0000^{*}$ & 47.73 & $(2,2064)$ & $0.0000^{*}$ \\
Gender $\times$ Stage & 1.18 & $(2,2057)$ & 0.3081 & 0.06 & $(2,2052)$ & 0.9415 & 0.94 & $(2,2064)$ & 0.3903 \\
\hline
\end{tabular}

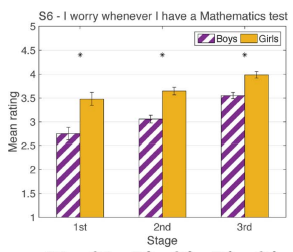

B1 $\underline{\text { G1 }} \underline{\text { B2 }} \underline{\mathrm{G} 2}$ B3 $\underline{\underline{\mathrm{G}} 3}$

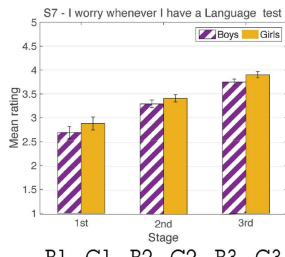

$\mathrm{Bl} \quad \mathrm{Gl} \quad \mathrm{B} 2 \mathrm{G} 2 \quad \mathrm{~B} 3 \mathrm{G} 3$

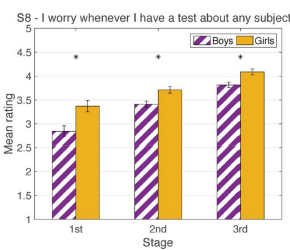

B1 G1 B2 G2 B3 G3
Fig. 5. Test anxiety. Left: mean ratings for $S 6$ ( $I$ worry whenever I have a mathematics test). Middle: mean ratings for $S 7$ (I worry whenever I have a Spanish language test). Right: Mean ratings for $S 8$ (I worry whenever I have a test, no matter the subject). Error bars show the standard error of the mean. Significant differences between both genders are marked with an asterisk. Girls are significantly more worried than boys in math tests, while in Spanish language tests there is no significant difference between genders. Below each graph, results for the pairwise comparisons are shown for the corresponding question (refer to the caption in Fig. 2).

396 whenever I have a test, no matter the subject) were consid397 ered. Results are presented in Table VII, and the main findings 398 are discussed next.

399 Gender has a significant effect on anxiety when facing 400 a math exam $(F=53.40, p<0.0001$ in $S 6)$, but not when 401 facing a Spanish language exam $[F(1,2052)=3.87, p=$ 4020.0493 in S7]. Post hoc tests for S6 show that in all three stages 403 gender has a significant effect, with boys providing signifi404 cantly lower ratings of test anxiety than girls $(p=0.0017$ in 405 the first, $<0.0001$ in the second, and 0.0001 in the third 406 stage). When looking at concern about exams, in general, gen407 der again has a significant effect $[F(1,2064)=27.50, p<$ 4080.0001 in $S 8$ ]; this significant difference is observed in all 409 three stages $(p=0.0191$ in the first, 0.0264 in the second, 410 and 0.0126 in the third stage). These effects are illustrated in ${ }_{411}$ Fig. 5, and can be contrasted with test anxiety in engineering ${ }_{412}$ students, where gender differences are not observed [50].

${ }_{413}$ The stage has a significant effect on all three questions 414 regarding test anxiety (see Table VII), with students' anxiety 415 increasing as stage increases (Fig. 5). Post hoc tests reveal that in $S 6$ there is a significant difference only between the third ${ }_{416}$ stage and the other two $(p<0.0001)$ for both genders. This is ${ }_{417}$ also the case for girls in $S 8$, whereas for boys, the three stages ${ }_{418}$ are significantly different: they experiment a larger increase in ${ }_{419}$ concern than girls, for whom the values were higher to begin 420 with. In $S 7$, all three stages are significantly different from ${ }_{421}$ each other for both genders.

422

The interaction effect between the gender of the student ${ }_{423}$ and the stage at which they are is nonsignificant for all three ${ }_{424}$ questions $S 6-S 8$ (Table VII), indicating there is no sign that ${ }_{425}$ boys' and girls' responses are influenced differently by stage. 426 Furthermore, considering students' preferences, gender differ- ${ }^{427}$ ences are maintained for learners without preference between ${ }_{428}$ math and Spanish Language. According to student's answers, 429 out of the girls with no preference between math and Spanish 430 language, $32.3 \%$ have a higher perceived self-efficiency in the ${ }_{431}$ Spanish language versus a $20.2 \%$ with higher self-efficiency ${ }_{432}$ in math. In the case of boys, only $17.1 \%$ of them have a higher ${ }_{433}$ self-efficiency in Spanish language versus a $37.8 \%$ in math. ${ }^{434}$ From these outcomes, it can be concluded that the general ${ }_{435}$ beliefs of boys and girls are kept also in learners that do not ${ }_{436}$ show any preference between Spanish language and math. In ${ }_{437}$ this group, it is also observed that $16.2 \%$ of the girls with- 438 out preference are more worried about math and $12.6 \%$ about 439 Spanish language, while $11.6 \%$ of the boys have higher anxiety 440 about math versus $20.1 \%$ in Spanish language.

\section{B. Relationship Between Teachers' Perception and Students' ${ }_{442}$ Beliefs \\ 443}

In order to determine, the teachers' consciousness of stu- 444 dents' self-perceived efficacy in math and the perceived 445 usefulness of math, teachers answered T6 (I think my stu- 446 dents understand the usefulness of mathematics) and T7 (I 447 have noticed that girls think they are worse than boys in 448 mathematics).

Almost 50\% of teachers consider that their students "very 450 often" $(41.13 \%)$ or "always" (9.93\%) understand the useful- 451 ness of mathematics. However, almost $85 \%$ of students admit 452 that they do very often $(27.7 \%)$ or always $(56.7 \%)$. It seems ${ }_{453}$ there may be a disconnection between students' and teachers' ${ }_{454}$ perceptions. However, the question posed to the students does 455 not ask if they believe mathematics is useful, but rather if 456 they understand what they are useful for; this nuance may be ${ }_{457}$ the cause of the disconnection. Teachers' perception is likely ${ }_{458}$ related to the fact that mathematics is more often tied to neg- 459 ative emotions like test anxiety rather than positive ones like 460 the enjoyment of the subject. In fact, Muis et al. [49] recom- ${ }_{461}$ mended that teachers highlight the importance and usefulness 462 of mathematics in order to help students' positive activating ${ }^{463}$ emotions.

Moreover, more than $50 \%$ of teachers think that girls 465 "never" consider themselves worse than boys in mathematics 466 when only $54.9 \%$ of the girls consider themselves very often ${ }^{467}$ or always good in mathematics as opposed to $71.5 \%$ of the ${ }_{468}$ boys. This means a gender difference of $16.6 \%$ that increases 469 to $21.3 \%$ when focused on the second and third stages. The 470 
471 present result shows that teachers are mostly unaware of gen472 der differences disadvantaging female students in children's 473 self-perceived efficacy in mathematics.

\section{4}

\section{Discussion}

475 Having found significant differences among primary school 476 students in the previous section, this section highlights the 477 implication of these quantitative results on the choice of sub478 sequent studies and the potential effect on women's interest in 479 STEM studies.

480 Mathematics has been chosen as the main subject to be 481 analyzed, as it is the one most related to engineering stud482 ies throughout the Spanish Primary School Curriculum. Other 483 subjects, such as natural science, contain relevant sections 484 at certain levels (e.g., electricity in the last two courses 485 of primary school) but are overall less related. The present 486 study analyzes three factors identified in the literature as 487 influencing the learning of mathematical concepts: 1) per488 ceived usefulness of math; 2) self-perceived efficacy; and 4893 ) test anxiety in math. Spanish language is also ana490 lyzed in order to compare tendencies between "engineering491 related subjects" and "nonengineering-related subjects." First, 492 looking into students' preferences, it can be observed that 493 from the second stage on, on average, boys prefer math 494 to Spanish language, whereas girls prefer Spanish language 495 to math, and there is a significant difference between gen496 ders. In contrast, no difference between genders nor stage is 497 observed in their preference for natural sciences versus social 498 sciences.

499 Second, students' perceived usefulness of math was ana500 lyzed through the statement $I$ understand what math is use501 ful for. No gender differences were observed (Fig. 3 and 502 Table IV). Throughout primary school, both girls and boys ${ }_{503}$ perceive math as very useful. However, teachers' perception of 504 students' understanding underestimated students' ratings. This 505 mismatch may be due to students usually exhibiting negative 506 emotions as test anxiety toward mathematics.

507 Third, the statements I am good at math and I am good 508 at Spanish language allowed an investigation of the self509 perceived efficacy of children in math and Spanish language 510 (Fig. 4 and Table V). Notable findings include that from the 511 second stage on, boys have a better self-perception than girls in 512 math, whereas girls have a better self-perception in Spanish 513 language. The trend becomes more pronounced as students 514 grow up, i.e., girls rate themselves significantly lower in math 515 in the third stage than in the second stage, and boys behave 516 similarly for Spanish language. These results are consistent 517 with precedent works that establish using explicit measures 518 that during primary school girls rate themselves lower than 519 boys in math [51] but not in reading or writing [52]. Besides, 520 a study with Singaporean primary-school students (math 521 achievements of students in Singapore is outstanding without 522 significant differences between genders) found higher implicit ${ }_{523}$ math self-concept in boys than girls [53]. Their findings sug${ }_{524}$ gest that even before young children's math achievement 525 becomes affected, their understanding of themselves in relation 526 to math is already beginning to be affected by sociocultural factors or stereotypical behaviors that may be prevalent in their ${ }_{527}$ community (i.e., gender differences in math self-concepts). $\quad{ }_{528}$

In addition, the results of the survey show that there is a cor- ${ }_{529}$ relation between children self-perceived efficacy in a specific ${ }_{530}$ domain (math or Spanish language) and children preferences 531 for that domain with respect to other domains; i.e., if a child ${ }_{532}$ considers her or himself good at mathematics and not so good ${ }_{533}$ at Spanish language, then that child will likely prefer math ${ }_{534}$ to Spanish language. Besides, girls prefer Spanish language ${ }_{535}$ to math while boys prefer math to Spanish language (see 536 Section III-A1 for more details).

Regarding teachers' perception on students' self-perceived- ${ }_{538}$ efficacy in mathematics, they apparently do not perceive such 539 large gender differences. It has been shown that gender stereo- 540 types in students' ability in mathematics exist in teachers ${ }_{541}$ even for very young students [13], and these are maintained ${ }_{542}$ throughout the education system with similar stereotypes held ${ }_{543}$ by high school teachers [54]. This stereotype is also present 544 in their students, as $54.9 \%$ of the girls versus $71.5 \%$ of the 545 boys consider themselves good in math always or "almost 546 always." This difference increases to $21.3 \%$ at the ages from 547 8 to 10 years old. However, the results of this work show 548 that teachers are not explicitly aware of their female stu- 549 dents' lack of confidence, with more than $50 \%$ of the teachers 550 believing that girls never consider themselves worse than their 551 male colleagues. This result may also imply that teachers 552 are not self-aware of their own stereotypes or the influ- 553 ence they have on their students. The disconnection between 554 teachers' views of students and students' self-perception is 555 potentially due to the fact that exam results show no signifi- 556 cant difference in math performance between male and female ${ }_{557}$ students [37], [55].

Teachers' opinions of individual students also have an influ- 559 ence over those pupils. Rosenthal and Jacobson [34] showed 560 that when teachers believe a student will show a strong 561 intellectual development that student's performance increases 562 highly irrespectively of her or his actual previous skills, espe- 563 cially in the early primary school years. The same study also 564 showed that for those students, female pupils showed higher 565 development in reasoning and male in verbal skills, the areas 566 most affected by stereotypes.

567

Finally, gender differences also arise regarding test anxiety 568 (Fig. 5 and Table VII). There is a significant difference in 569 self-reported anxiety in math exams between boys and girls, 570 with girls reporting higher anxiety scores. Interestingly, this 571 trend is not found in Spanish language exams, where there is 572 no significant effect of gender in self-reported anxiety for the 573 first, second, and third stages. Additionally, self-reported test 574 anxiety increases as students progress through primary school, 575 particularly in the third stage with respect to the other two. 576 Anxiety has been argued to be a mediating variable of stereo- 577 type threat. The stereotype threat theory (STT) [56] states 578 that if negative stereotypes are present regarding a specific 579 group, group members are likely to become anxious about 580 their performance, which may hinder their ability to perform 581 to their full potential. Stereotype threat has been found to ${ }_{582}$ be a contributing factor to longstanding racial and gender 583 gaps in academic performance [57]. It has been extensively 584 
585 studied [58] and has been found not only in the labora586 tory but also in classroom settings [59]. Strong math-gender 587 stereotypes have been found to correlate with stronger math 588 self-concepts for boys and weaker math self-concepts for 589 girls [53]. As stated, teachers have shown stereotypes toward 590 gender in numerous occasions [13], [36]. Therefore, for girls, 591 the development of a math self-concept that supports high 592 math achievement may require opposing the effects of hav593 ing acquired the societally stereotypical connection between 594 math and boys [60]. Once stereotypes are internalized, stu595 dents may begin to devalue particular school subjects; not 596 because they have experienced difficulties with those subjects 597 in the past, but because the stereotypes connote that they may 598 experience difficulties in the future [61]. If explicit percep599 tions of academic discipline are at odds with one's identity 600 they discourage students from choosing and identifying them601 selves with the field [62], [63]. Even if young girls excel in 602 primary-school mathematics, as in Singapore, the stereotype 603 that math is for boys might bias girls not to pursue mathemat604 ics in the long run, affecting girls educational interests and 605 career choices in the future [45], [64], [65] and contributing 606 to female underrepresentation in STEM fields.

607 There are many outreach activities for high-school students, 608 such as Girls' Day [7] or Technovation Challenge [66], which 609 have been running during more than ten years without strong 610 effects. Findings support that girls become less interested in 611 STEM topics when they move from the primary to secondary 612 school [67], and that teachers have a stronger influence over 613 their students in the younger years [34]. The effect of teach614 ers paired with their implicit stereotypes and the unawareness 615 of girls' self-perceptions indicates a potential area for devel616 opment. It is a strongly suggested that changing teachers' 617 perceptions of students' and girls' mathematical ability will 618 lead to an increase in females' self-perception in this sub619 ject. Moreover, these facts together with the present study 620 imply that interventions should focus on changing teachers' 621 and students' beliefs and attitudes about math in primary 622 school stages, when interventions may be most effective due 623 to the malleability of stereotypes and students' emerging 624 self-concepts [53].

\section{V. CONClusion AND Future ACtions}

626 The lack of women's presence in STEM studies is a global 627 problem, receiving considerable attention in the last years. ${ }_{628}$ Recent studies have shown that girls become less interested 629 than boys in STEM topics during adolescence; therefore, 630 this work has analyzed through a large-scale study com631 prising more than 2100 students, 212 teachers, and a total 632 of 17520 answers, gender differences that may arise during 633 early stages of education (i.e., throughout primary school). 634 Math subject is the main focus of the study since it has 635 been identified in the literature as highly correlated with the ${ }_{636}$ lack of female students in STEM university degrees. Gender 637 and educational stage's influence in math perception are ana638 lyzed, in terms of perceived usefulness, preference with respect 639 to another subject, self-perceived efficacy, and test anxiety.
Whenever appropriate, these aspects are compared to simi- 640 lar perceptions for Spanish language subject in order to have 641 a relative measure as opposed to an absolute one. 642

Results show remarkable differences between genders, with 643 girls presenting a lower perceived self-perceived efficacy in 644 math than boys and significantly higher test anxiety. These 645 trends increase along educational stages as students grow up. 646

These findings suggest that girls are less likely to experience 647 positive activating emotions during the mathematics learning 648 process at primary school, often due to their teachers' unin- 649 tended influence. This early childhood experience may affect 650 girls' attitude toward mathematics at the high school level, 651 increasing the anxiety levels in many girls. Consequently, it 652 is more likely for them to avoid studies with mathematical 653 requirements, such as STEM degrees. Primary-school teach- 654 ers are not aware of this situation or of their implicit bias, so 655 it cannot be expected that they accomplish actions to reverse 656 the situation. Potential unawareness of the teachers can lead 657 to difficulties in reversing this issue.

658

From these findings, the following recommendations in 659 order to promote more women in STEM emerge. It is nec- 660 essary, particularly during the early stages of education (i.e., 661 primary school) to: $\quad 662$

1) work on teachers' awareness of girls' lack of self- 663 confidence toward mathematics; 664

2) accomplish actions in order for students, especially 665 girls, to experience positive activating emotions toward 666 mathematics;

3) give explicit messages about the value of mathematics 668 in a real-world context.

To summarize, it is essential to make teachers aware of the 670 problem and of their actions very powerful effects, and how 671 they may influence students' beliefs. Schools have to actively 672 promote gender balance in all areas, making all stakeholders 673 work in the same direction. The authors will continue organiz- 674 ing and promoting "A Female Engineer in Every School," as 675 it is an activity that can help close the gender gap in STEM. 676

\section{ACKNOWLEDGMENT}

The authors would like to thank all volunteers and partici- 678 pants in "A Female Engineer in Every School."

679

\section{REFERENCES}

[1] Education at a Glance 2018. Paris, France: OECD Publ., 2018, p. 460. 681

[2] C. Botella, S. Rueda, E. López-Iñesta, and P. Marzal, "Gender diver- 682 sity in STEM disciplines: A multiple factor problem," Entropy, vol. 21, 683 no. 30, pp. 1-17, 2019.

[3] M. T. Wang and J. L. Degol, "Gender gap in science, technology, engi- 685 neering, and mathematics (STEM): Current knowledge, implications for 686 practice, policy, and future directions," Educ. Psychol. Rev., vol. 29, 687 no. 1, pp. 119-140, 2017.

[4] M. Klawe, T. Whitney, and C. Simard, "Women in computing-take 2," 689 Mag. Commun. ACM Inspiring Women Comput., vol. 52, no. 2, 690 pp. 68-76, 2009.

[5] Employment in Technology and Knowledge-Intensive Sectors at the 692 National Level, by Sex (From 2008 Onwards, NACE Revision 2), 693 Eurostat, Brussels, Belgium, 2017.

[6] Current Population Survey, Household Data Annual Averages 2016, 695 Bureau Labor Stat, Washington, DC, USA, 2017.

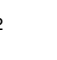

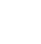

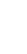

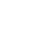

(1)

(1)


[7] P. Molina-Gaudó, S. Baldassarri, M. Villarroya-Gaudó, and E. Cerezo, "The perception and intention in relation to engineering: A gendered study based on a one-day outreach activity," IEEE Trans. Educ., vol. 53, no. 1, pp. 61-70, Feb. 2010.

[8] J. C. Blickenstaff, "Women and science careers: Leaky pipeline or gender filter?" Gender Educ., vol. 17, no. 4, pp. 369-386, 2005.

[9] M. T. Wang, J. S. Eccles, and S. Kenny, "Not lack of ability but more choice: Individual and gender differences in choice of careers in science, technology, engineering, and mathematics," Psychol. Sci., vol. 24, no. 5, pp. 770-775, 2013.

[10] J. Herbert and D. Stipek, "Are computer science and information technology still masculine fields? High school students' perceptions and career choices," Comput. Educ., vol. 51, no. 2, pp. 594-608, 2008.

[11] D. I. Miller, A. H. Eagly, and M. C. Linn, "Women's representation in science predicts national gender-science stereotypes: Evidence from 66 nations," J. Educ. Psychol., vol. 107, no. 3, pp. 631-644, 2015.

[12] S. Leslie, A. Cimpian, M. Meyer, and E. Freeland, "Women are underrepresented in disciplines that emphasize brilliance as the key to success," Sci., vol. 347, no. 6, pp. 262-265, 2015.

[13] J. Robinson-Cimpian, S. Theule Lubienski, C. Ganley, and Y. Copur-Gencturk, "Teachers' perception of students' mathematics proficiency may exacerbate early gender gaps in achievement," Develop. Psychol., vol. 50, no. 4, pp. 1262-1281, 2014.

[14] L. Bian, S. L. Leslie, and A. Cimpian, "Gender stereotypes about intellectual ability emerge early and influence children's interests," Science, vol. 355, no. 6323, pp. 389-391, 2017.

15] G. Park, D. Lubinski, and C. P. Benbow, "Contrasting intellectual patterns predict creativity in the arts and sciences: Tracking intellectually precocious youth over 25 years," Psychol. Sci., vol. 18, no. 11, pp. 948-952, 2007.

16] J. M. Valla and S. J. Ceci, "Breadth-based models of women's underrepresentation in STEM fields: An integrative commentary on Schmidt (2011) and Nye et al. (2012)," Perspect. Psychol. Sci., vol. 9, no. 2, pp. 219-224, 2014.

[17] E. A. P. Cass, Z. Hazari, J. Cribbs, P. M. Sadler, and G. Sonnert, "Examining the impact of mathematics identity on the choice of engineering careers for male and female students," in Proc. Frontiers Educ. Conf., 2011, pp. 1-5.

[18] M. Sainz and J. Müller, "Gender and family influences on Spanish students' aspirations and values in stem fields," Int. J. Sci. Educ., vol. 40, no. 2, pp. 188-203, 2018.

[19] G. Ramirez, E. A. Gunderson, S. C. Levine, and S. L. Beilock, "Math anxiety, working memory, and math achievement in early elementary school," J. Cognition Develop., vol. 14, no. 2, pp. 187-202, 2012.

[20] C. B. Young, S. S. Wu, and V. Menon, "The neurodevelopmental basis of math anxiety," Psycol. Sci., vol. 23, no. 5, pp. 492-501, 2012.

[21] The ABC of Gender Equality in Education: Aptitude, Behaviour Confidence (PISA). Paris, France: OECD Publ., 2015, p. 180.

[22] L. O'Keeffe, L. White, D. Panizzon, K. Elliott, and A. Semmens, "Mathematics anxiety: Year 7 and 8 student perceptions," in Proc. 41st Annu. Conf. Math. Educ. Res. Group Australasia (MERGA), 2018, pp. 607-614.

[23] A. Efklides and S. Volet, "Feelings and emotions in the learning process," Learn. Instruct., vol. 15, no. 5, pp. 377-515, 2005.

[24] E. A. Linnenbrink, "Emotion research in education: Theoretical and methodological perspectives on the integration of affect, motivation, and cognition," Educ. Psychol. Rev., vol. 18, no. 4, pp. 307-314, 2005.

[25] P. A. Schutz and R. Pekru, Eds., Emotion in Education (A Volume in Educational Psychology Series). Burlington, VT, USA: Elsevier, 2007, p. 368.

26] S. Shukajlow and K. Rakoczy, "The power of emotions: Can enjoyment and boredom explain the impact of individual preconditions and teaching methods on interest and performance in mathematics?" Learn. Instruct., vol. 44, pp. 117-127, Aug. 2016.

[27] R. Hembreee, "The nature, effects, and relief of mathematics anxiety," J. Res. Math. Educ., vol. 21, no. 1, pp. 33-46, 1990.

28] H. Ho et al., "The affective and cognitive dimensions of math anxiety: A cross-national study," J. Res. Math. Educ., vol. 31, no. 3, pp. 362-380, 2000 .

[29] T. M. Beasley, J. D. Long, and M. Natali, " A confirmatory factor analysis of the mathematics anxiety scale for children," Meas. Eval. Counseling Develop., vol. 34, no. 1, pp. 14-26, 2001.

[30] M. H. Ashcraft and K. S. Ridley, " Math anxiety and its cognitive consequences-A tutorial Rev.," in Handbook of Mathematical Cognition. New York, NY, USA: Psychol. Press, 2005, pp. 315-327.
[31] T. Mainhard, S. Oudman, L. Hornstra, and R. J. Bosker, "Student emo- 772 tions in class: The relative importance of teachers and their interpersonal 773 relations with students," Learn. Instruct., vol. 53, no. 1, pp. 109-119, 774 2018.

[32] E. S. Becker, T. Goetz, V. Morger, and J. Ranellucci, "The impor- 776 tance of teachers' emotions and instructional behavior for their students' 777 emotions-An experience sampling analysis," Teach. Teacher Educ., 778 vol. 43, pp. 15-26, Oct. 2014.

[33] F. Cubukcu, "The significance of the academic emotions," Procedia Soc. 780 Behav. Sci., vol. 70, pp. 649-653, Jan. 2013.

[34] R. Rosenthal and L. Jacobson, "Pygmalion in the classroom," Urban 782 Rev., vol. 3, pp. 16-20, Sep. 1968.

[35] S. L. Beilock, E. A. Gunderson, G. Ramirez, and S. C. Levine, "Female 784 teachers' math anxiety affects girls'math achievement," Proc. Nat. Acad. 785 Sci. USA, vol. 107, no. 5, pp. 1860-1863, 2010.

36] E. Denessen, N. Vos, F. Hasselman, and M. Louws, "The relationship 787 between primary school teachers and students attitudes towards science 788 and technology," Educ. Res. Int., vol. 2015, Feb. 2015, Art. no. 534690. 789

[37] Gobierno de Aragón, "Report of diagnostic evaluation results. 790 Course 2017/18," Departamento de Educación, Cultura y 791 AQ6 Deporte, Evaluación Educativa Aragón, 2018. Accessed: Jun. 18, 792 2020. [Online]. Available: http://evalua.catedu.es/evaluacion/wp- 793 content/uploads/InformeGeneral2017_2018.pdf

[38] E. Cerezo et al., "A female engineer in every school," in Proc. 21st Int. 795 Conf. Human Comput. Interact. (Interacción), Palma, Spain, 2018, p. 2. 796

[39] A. J. Little and B. A. León de la Barra, "Attracting girls to science, 797 engineering and technology: An Australian perspective," Eur. J. Eng. 798 Educ., vol. 34, no. 5, pp. 439-445, 2009.

[40] A. G.-V. Muñoz-Repiso and V. B. Gómez-Pablos, "Evaluación de una 800 experiencia de aprendizaje colaborativo con Tic desarrollada en un cen- 801 tro de educación primaria,' Revista Electrónica de Tecnología Educativa 802 (EDUTEC), vol. 51, pp. 1-12, Mar. 2015.

[41] A. García-Varcárcel, V. Basilotta, and C. López, "ICT in collabora- 804 tive learning in the classrooms of primary and secondary education," 805 Comunicar, vol. 21, no. 42, pp. 65-74, 2014.

[42] D. Llewellyn, S. Pray, R. DeRose, and W. Ottman, "Engineering encoun- 807 ters: Building a spaghetti structure," Sci. Children, vol. 54, no. 2, 808 pp. 70-75, 2016.

[43] Laughing Squid. (May 2, 2016). How to Build a Simple DIY Plastic 810 Foam Cutter Using a Nine-Volt Battery and Some Wire. Accessed: Jun. 811 18, 2020. [Online]. Available: https://laughingsquid.com/diy-plastic- 812 foam-cutter/

[44] Water Filter Mag. (Feb. 2, 2020). DIY Water Filtration System-Basics 814 \& Tips for Beginners. Accessed: Feb. 3, 2020. [Online]. Available: 815 https://www.waterfiltermag.com/diy-water-filter/

[45] Imascono. (Feb. 1, 2019). Educational Augmented Reality 817 App for Kids. Accessed: Jun. 18, 2020. [Online]. Available: 818 https://imascono.com/portfolio-item/augmented-reality-kids-chromville 819

[46] (Mar. 8, 2019). CS UnpluggedAccessed: Jun. 18, 2020. [Online]. 820 Available: https://csunplugged.org/en/topics/image-representation/ 82

[47] I. A. E. (Aragonese Insitute of Statistics), Educación y Formación: 82 Indicadores de la enseñanza no universitaria. (1.3 y 1.4), 2018.

[48] B. Flyvbjerg, Qualitative Research in Practice, C. Seale, G. Gobo, 824 J. F. Gubrium, and D. Silverman, Eds. London, U.K.: Sage, 2004, 825 pp. 420-434.

[49] K. R. Muis, C. Psaradellis, S. P. Lajoie, I. D. Leo, and M. Chevrier, 827 "The role of epistemic emotions in mathematics problem solving," 828 Contemporary Educ. Psychol., vol. 42, pp. 172-185, Jul. 2015.

[50] M. Alves, C. S. Rodrigues, A. M. A. C. Rocha, and C. Coutinho, "Self- 830 efficacy, mathematics' anxiety and perceived importance: an empirical 831 study with Portuguese engineering students," Eur. J. Eng. Educ., vol. 41, 832 no. 1, pp. 105-121, 2016.

[51] J. Herbert and D. Stipek, "The emergence of gender differences in chil- 834 dren's perceptions of their academic competence," J. Appl. Develop. 835 Psychol., vol. 26, no. 3, pp. 276-295, 2005.

[52] F. Pajares, M. D. Miller, and M. J. Johnson, "Gender differences in 837 writing self-beliefs of elementary school students," J. Educ. Psychol., 838 vol. 91, no. 1, pp. 50-61, 1999.

[53] D. Cvencek, M. Kapur, and A. Meltzoff, "Math achievement, stereo- 840 types, and math self-concepts among elementary-school students in 841 Singapore," Learn. Instruct., vol. 39, pp. 1-10, Oct. 2015.

[54] C. Riegle-Crumb and M. Humphries, "Exploring bias in math teachers' 843 perceptions of students' ability by gender and race/ethnicity," Gender 844 Soc., vol. 26, no. 2, pp. 290-322, 2012.

[55] J. Hutchison, I. Lyons, and D. Ansari, "More similar than different: 846 gender differences in children's basic numerical skills are the exception 847 not the rule," Child Develop., vol. 90, no. 1, pp. e66-e79, 2019. 
849 [56] C. M. Seele, "A threat in the air. How stereotypes shape intellectual 850 identity and performance," Amer. Psychol., vol. 52, no. 6, pp. 613-629, 1997.

852 [57] C. M. Steele and J. Aronson, "Stereotype threat and the intellec-tual test

88 Natalia Ayuso (Member, IEEE) received the Ph.D. degree in 2010.

888 She is an Associate Professor with the Department of Computer Science, 889 Universidad de Zaragoza, Zaragoza, Spain. Her research interests focus on 890 electromagnetic field propagation in challenging environments as caves, tun891 nels, or mines for subsurface location and communication in constrained 892 sceneries for robotics as well as in wireless sensor networks in confined 893 environments.

894 Dr. Ayuso is a member of AMIT (Spanish Association of Women 895 Researchers and Technologists).

904 Belén Masiá (Member, IEEE) received the Ph.D. degree in 2013.

She is an Assistant Professor with the Department of Computer Science, 906 Universidad de Zaragoza, Zaragoza, Spain. Her research focuses on compu907 tational imaging, applied perception, and virtual reality.

908 Dr. Masiá is also a recipient of the Eurographics Young Researcher Award 909 in 2017 and the NVIDIA Graduate Fellowship in 2012. She serves as an 910 Associate Editor for the ACM Transactions on Graphics. She is a Eurographics 911 Junior Fellow and a member of AMIT.

Elena Fillola was born in Zaragoza in 1999. She is currently pursuing the 897 M.Eng. degree in engineering mathematics with the University of Bristol, 898 Bristol, U.K.

899 She is Outreach Representative for the Society of Women in Engineering,

902 Dr. Fillola is a member of AMIT (Spanish Association of Women 903 Researchers and Technologists).
Ana C. Murillo (Member, IEEE) received the Ph.D. degree in computer 912 science from the University of Zaragoza, Zaragoza, Spain.

She is currently an Associate Professor with the Department of Computer 914 Science and Systems Engineering, Universidad de Zaragoza. Her research 915 interests include scene understanding and visual recognition for robotics and 916 other embedded systems.

Dr. Murillo is a member of the Aragonese Professional College of 918 Engineering in Computer Science and AMIT (Spanish Association of Women 919 Researchers and Technologists).

Raquel Trillo-Lado received the Ph.D. degree in 2012.

She is an Associate Professor with the Department of Computer Science 922 and Systems Engineering, University of Zaragoza, Zaragoza, Spain. Her 923 research interests include digital data management and keyword search on 924 structured data sources.

Dr. Trillo-Lado is a member of SISTEDES, SERI, the Aragonese 926 Professional College of Engineering in Computer Science, and AMIT.

Sandra Baldassarri (Senior Member, IEEE) received the Ph.D. degree in 928 computer science engineering from the University of Zaragoza, Zaragoza, 929 Spain, in 2004.

She is an Associate Professor with the Computer Science Department, 931 University of Zaragoza. Her research interests include virtual humans, affec- 932 tive computing, multimodal interfaces, tangible and natural interaction, and 933 their application in educational fields.

Dr. Baldassarri is a member of AMIT (Spanish Association of Women 935 Researchers and Technologists). She serves as an Associate Editor for IEEE 936 ACCESS.

Eva Cerezo (Member, IEEE) received the Ph.D. degree in computer science 938 in 2002.

She is an Associate Professor with the Computer Science Department, 940 University of Zaragoza, Zaragoza, Spain. She leads the AffectiveLab, Tokyo, 941 Japan, a research group that focuses on affective multimodal human computer 942 interaction, tangible tabletops, and virtual humans. She has authored more than 943 80 international publications.

Dr. Cerezo is the Head of the Executive Board of the ACM SIGCHI 945 Spanish Local Chapter and a member of AMIT (Spanish Association of 946 Women Researchers and Technologists).

Laura Ruberte received the Ph.D. degree in 1985.

948

She is an Associate professor with the Department of Analytical Chemistry, 949 Universidad of Zaragoza, Zaragoza, Spain. Her research focuses on chemical 950 analysis.

Dr. Ruberte is a member of SEQA (Spanish Society of Analytical 952 Chemistry) and AMIT (Spanish Association of Women Researchers and 953 Technologists). 901 data science.
M. Dolores Mariscal is an Associate Professor with the Department of 955 Science and Technology of Materials and Fluids, University of Zaragoza, 956 Zaragoza, Spain.

Dr. Mariscal is a member of AMIT (Spanish Association of Women 958 Researchers and Technologists).

María Villarroya-Gaudó received the Ph.D. degree from the Department 960 of Electronics Engineering, Autonoma University of Barcelona, Bellaterra, 961 Spain, in 2005.

She is an Associate Professor of computer architecture and technology 963 with the Department of Computer and Systems Engineering, Universidad de 964 Zaragoza, Zaragoza, Spain. Her research interests include memory hierarchy 965 and heterogeneous systems.

Dr. Vilarroya-Gaudó is a member of the Spanish Society of Computer 967 Architecture (SARTECO) and the President of AMIT-Aragón (Asociación 968 Mujeres Investigadoras y Tecnólogas en Aragón). 